\title{
Resolution of Proteinuria in Lupus Nephritis: Hurry Up and Wait
}
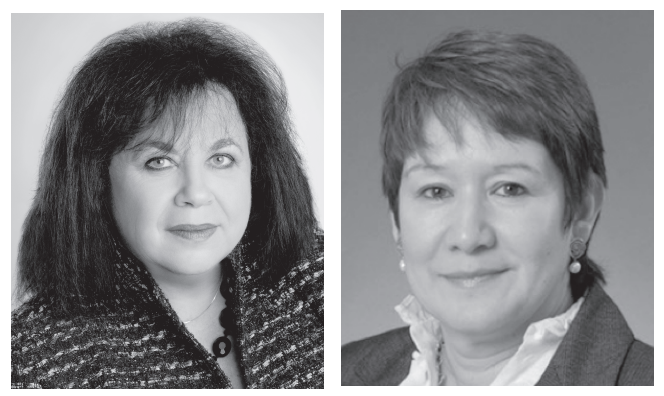

In this issue of The Journal, Touma and colleagues map out the time to improvement or resolution of proteinuria in a historical cohort of patients with lupus nephritis (LN) ${ }^{1}$. More than 200 patients entered in the University of Toronto Lupus Clinic database and followed between 1970 and 2011 constituted the cohort for this analysis. Regardless of the time from the original diagnosis of lupus, the first identified onset of proteinuria functioned as the baseline for this study. From that point onward, the time it took for recovery of proteinuria was measured. Recovery was defined as a $24 \mathrm{~h}$ urine protein of $<0.5 \mathrm{~g}$. If a $24 \mathrm{~h}$ urine collection was not available, urine dipstick for albumin, or a random urine protein to creatinine ratio was used. For the Kaplan-Meier analysis of proteinuria over time, the maximum followup was 5.5 years. If a patient still had proteinuria at this time, the data were censored. Interestingly, the mean duration of lupus before the onset of proteinuria was more than 5 years.

None of the baseline characteristics, renal or extrarenal, predicted who would recover from proteinuria. Even the subgroup of patients with true nephrotic-range proteinuria had the same degree of ultimate resolution compared to those with subnephrotic protein excretion. Not surprisingly, the greater the proteinuria at baseline, the longer it took for recovery (the further you live from home, the longer it takes to get there). The presence of persistently low complement levels was associated with increased time to recovery, which again makes sense, as it can reflect either more aggressive, treatment-resistant disease or non-adherence to therapy. Biopsy class also did not appear to influence resolution or time to resolution, although it is regrettable that 20 patients with biopsy-proven lupus membranous nephropathy were excluded from analysis because of the absence of "active" urinary sediment. This speaks to the difference in significance placed on the presence of urinary casts by rheumatologists (very important) and nephrologists (not so important $)^{2}$.

The most important finding of this study is that it takes a surprisingly long time for most patients to achieve resolution of proteinuria. In the first year of followup, little more than one-quarter of patients experienced this endpoint. After another year, recovery was up to half, and reached $74 \%$ at the end of 5 years. The lesson here: What is needed, for healing and repair of the glomerular capillary barrier, is time.

Glomerular damage associated with immune-complex deposition involves a combination of direct and indirect tissue injury that leads to a host of responses. Tissue response involves clotting, inflammation, epithelial regeneration, and mesenchymal repair by fibrosis or sclerosis. These processes occur serially during the acute phase, with some overlap (reviewed in Hagemann, et $a l^{3}$ ). However, under the continuous generation of immune complexes, as frequently happens in LN, this overlap leads to persistence of some of these mechanisms, e.g., inflammation and healing, which often leads to glomerular scarring, significant parenchymal atrophy, and fibrosis ${ }^{3}$.

The persistence of classically activated mononuclear phagocytes or repetitive/persistent triggers of kidney injury also impairs epithelial repair in the tubulointerstitial compartment ${ }^{4}$. In addition, severe or continuous kidney injury may eradicate tubular progenitor cells ${ }^{3}$. Insufficient regeneration of injured tubular epithelial cells leads to tubular atrophy and nephron loss, characteristic of progressive chronic kidney disease ${ }^{5}$. Therefore, coordinated epithelial regeneration is needed in response to injury, which first requires vascular sealing and the resolution of inflammation. Loss of glomerular visceral epithelial cells (podocytes) cannot be easily repaired, leading to segmental glomerular scarring ${ }^{5,6}$. Mesangial cells contribute to the sclerosis by excess production of mesangial matrix ${ }^{7}$. Podocytes undergo apoptosis in immune complex-mediated glomerular disease induced by overexpression of transforming growth factor- $\beta$ (TGF- $\beta)^{3}$. Parietal epithelial cells produce extracellular matrix, contributing to the segmental areas of glomerular scarring ${ }^{8}$. Unfortunately, the scarring process acquires its own dynamic and progresses to global

\section{See Recovery from proteinuria in lupus nephritis, page 688}


glomerulosclerosis, even when the original insult has resolved $^{9}$. Finally, compensatory hyperfiltration of the remaining glomeruli adds more hemodynamic stress on the surviving podocytes ${ }^{9}$.

$\mathrm{LN}$ is a histopathological entity resulting from the deposit of immune complexes at different locations in the glomerulus. Proteinuria is a major feature of $\mathrm{LN}$ and reflects injury of the podocytes ${ }^{10}$. Protein in the urine can be the result of immune complexes sited along the glomerular basement membrane (GBM), or the result of subendothelial immune deposits, endothelial cell swelling, podocyte damage, or scarring and remodeling of the GBM. Additionally, proteinuria is a major mediator of progressive interstitial fibrosis in any chronic proteinuric disorder ${ }^{10}$.

Therefore renal epithelial cells determine much of the kidney's functions in the glomerular compartment (filtration barrier) as well as in the tubular compartment of the kidney (reabsorption and secretion). Loss of podocyte regeneration is the predominant cause of chronic dysfunction, persistent proteinuria, and progression to chronic kidney disease ${ }^{11}$.

C5b-9 formation and insertion into podocyte cell membranes causes glomerular injury ${ }^{12}$. The continuous presence of the immune complexes will generate the consecutive remodeling of the GBM as an attempt at healing ${ }^{3,12}$. Subepithelial immune deposits against anti-dsDNA, anti-nucleosomes, and nephritogenic autoantibodies to laminin and collagen IV as well as other, largely unidentified antigens initiate podocyte injury in LN, activating complement ${ }^{13}$. C5b-9 in sublytic quantities stimulates podocytes to produce proteases, oxidants, prostanoids, extracellular matrix components, and cytokines including TGF- $\beta^{12}$. These events result in disruption of the functional integrity of the glomerular basement membrane and the protein filtration barrier, with subsequent development of proteinuria ${ }^{3}$. Complement components in the proteinuric urine also induce tubular epithelial cell injury and mediate progressive interstitial disease ${ }^{12,14}$.

Glomerular capillary hypertension is a common denominator in various forms of progressive glomerular disease, including immune-complex mediated glomerulonephritis $(\mathrm{GN})^{9}$. There is an increase in the number of apoptotic podocytes after mechanical stretch secondary to hyperfiltration $^{13,15}$, and it is likely that upregulation of local angiotensin II production, and expression of angiotensin type 1 receptor in podocytes by mechanical strain is responsible ${ }^{13}$. These observations provide a rationale for the inhibition of angiotensin II, a major mediator of increased glomerular pressure, in patients with lupus immune-complex mediated GN by the use of angiotensin-converting inhibitors or angiotensin receptor blockers ${ }^{15}$. All of these findings suggest that, in the presence of glomerular hypertension, mechanical stretch may aggravate podocyte injury induced by antibody and complement ${ }^{16}$.
Recognition of podocyte biology and complex inflammatory/healing mechanisms in lupus injury is essential for understanding the "incomplete" response to therapy and the presence of proteinuria even in the absence of activity of the disease. Loss of podocytes in combination with limitations in their compensatory proliferation in response to injury, as well as the presence of residual inflammation and remodeling of the GBM may be responsible for persistent proteinuria in the absence of further activity of the original insult. Further, tubular dysfunction leads to reduced reabsorption of protein that passes through the glomerular capillary barrier, leading to proteinuria, even in the face of minor glomerular abnormalities. Therefore, persistent or residual proteinuria may not be the ideal characteristic for monitoring response to therapy or making therapeutic decisions in $\mathrm{LN}$.

There is an important lesson to be learned from primary (non-lupus) membranous nephropathy, where the causative antibody [anti-phospholipase-A2 receptor $\left.\left(\mathrm{aPLA}_{2} \mathrm{R}\right)\right]$ has been isolated ${ }^{17}$. It is clear from the time course of the $\mathrm{aPLA}_{2} \mathrm{R}$ level in the blood that there is a lag between disappearance of the causative antibody and the improvement in the proteinuria (Figure 1). It may not make sense to subject patients to intensive immunosuppressive therapy once the antibody is no longer measureable. However the patient who continues to receive therapy based on the degree of proteinuria would be exposed to the risks of immunosuppression during this antibody-negative lag phase. In lupus nephropathy, because the causative antibody is unknown and unmeasurable, many (if not most) clinicians continue to press on with immunosuppression in the face of continuing proteinuria, when perhaps production and circulation of the culprit antibody has regressed and aggressive immunosuppression is no longer necessary. In other words, the active immune-mediated inflammation has been appropriately treated, but it takes time for the proteinuria to resolve; and scarring or tubulointerstitial fibrosis may mean that the proteinuria never completely goes away.

The delay in resolution of proteinuria is not unique to the data of Touma, et $a l^{1}$. In a recent review of outcome of both pure lupus membranous and mixed membranous/proliferative nephritis in 103 patients in Italy, it also took years for either nephritis to remit completely (Figure 2). By 17 months, half the mixed nephritis group was in renal remission, and it took 3 years to achieve remission in 50\% of patients with pure lupus membranous nephropathy ${ }^{18}$. Similarly, a combined analysis of the small number of patients with lupus membranous nephritis included in the American study of mycophenolate mofetil (MMF) versus cyclophosphamide and the ALMS trial showed that at 24 weeks the $24 \mathrm{~h}$ urine protein was approximately $2 \mathrm{~g}$ no matter which therapy was received ${ }^{19,20}$.

The MAINTAIN trial examined the endpoint of renal flare after induction therapy with $3 \mathrm{~g}$ of intravenous cyclo-

Personal non-commercial use only. The Journal of Rheumatology Copyright @ 2014 . All rights reserved. 


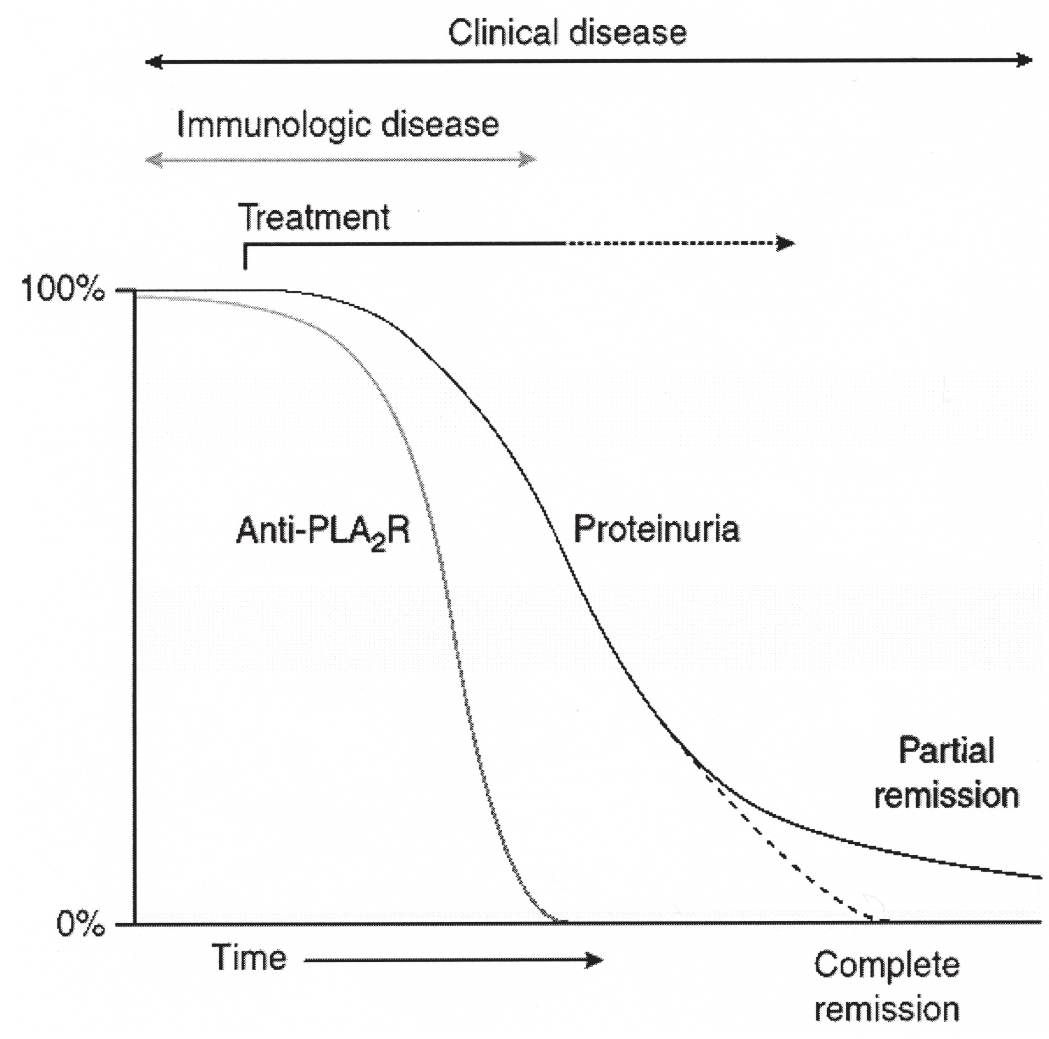

Figure 1. Relationship between clinical disease and immunologic activity. In the example of primary membranous nephropathy, the disappearance of the causative antibody is followed by an eventual reduction of proteinuria that is separated by a lag phase. Reprinted from Beck and Salant. Kidney Int 1010;77:765-70; with permission.

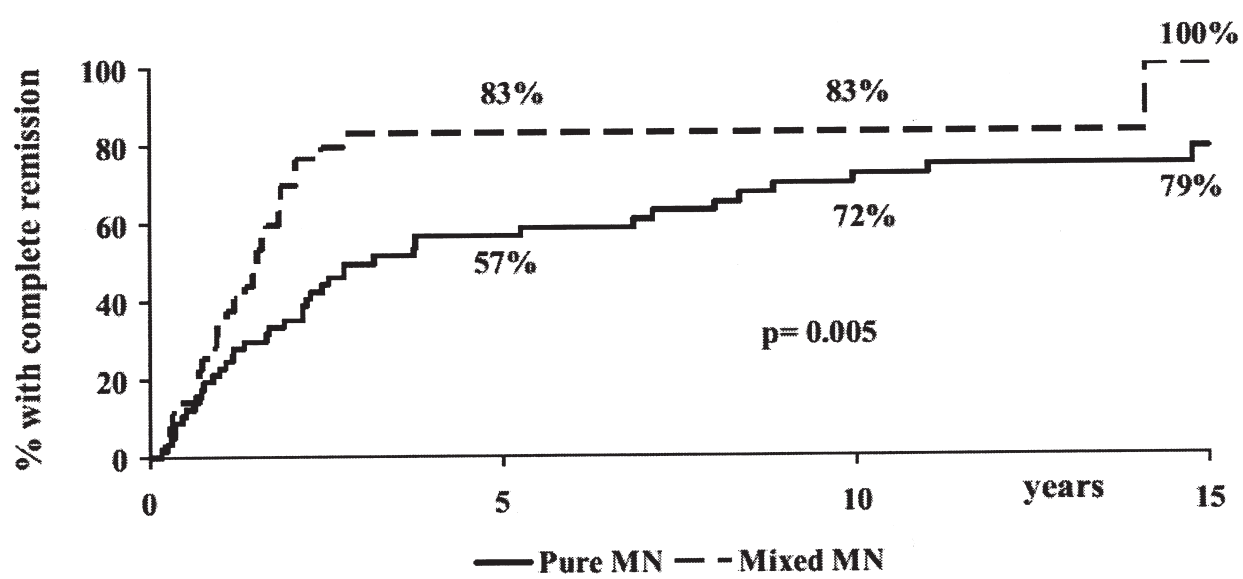

Figure 2. In both pure lupus membranous nephropathy and mixed membranous/proliferative disease, the resolution of proteinuria occurs gradually over several years. Reprinted from Moroni, et al. Semin Arthritis Rheum 2012:41:642-51; with permission.

phosphamide and glucocorticoid over 12 weeks, followed by "maintenance" with either azathioprine or $\mathrm{MMF}^{21}$. It is interesting that at 12 weeks the $24 \mathrm{~h}$ urine protein (after the high dose corticosteroid and fortnightly cyclophosphamide regimen) was still $3 \mathrm{~g}$. In this study, the renal response was defined not by disappearance of proteinuria, but a $>50 \%$ reduction. While there was a slow continuous reduction in $24 \mathrm{~h}$ protein, it appears from the figures that, on average, the value oscillated between 0.5 and $1.0 \mathrm{~g}$ at 36 months ${ }^{21}$.

In the ALMS study mentioned above, the majority of patients had proliferative lupus nephritis ${ }^{20}$. It is important to note that at the end of the induction period of 24 weeks, less 
than $9 \%$ of the patients met all the criteria for renal remission. Although the criterion for resolution of proteinuria was generous (in patients with nephrotic-range protein excretion, a decrease to $<3 \mathrm{~g} /$ day; in patients with baseline subnephrotic proteinuria, a decrease $>50 \%$ ) only about $25 \%$ of patients achieved even this goal. In the extension phase of this trial, where patients were rerandomized to maintenance therapy with either MMF or azathioprine ${ }^{22}$, the endpoint of the study was to prevent renal relapse. However, it was noted that patients receiving either drug continued to improve over time so that eventually about $60 \%$ of patients sustained complete remission. As the authors commented "This finding suggests that the distinction between induction therapy and maintenance therapy in patients with lupus nephritis may be an artificial one"22.

In the studies discussed above, the primary renal endpoint was time to relapse, and it is only upon closer scrutiny that the surprising length of time becomes clear that it takes for improvement in renal indices. Touma and colleagues have added importantly to the literature by putting the focus of their study on the length of time needed for healing of the glomeruli and resolution of proteinuria. The Germans have an expression for this: Abwarten und Tee trinken, which means "sit back and drink tea." This may be an important lesson for clinicians managing lupus nephritis. In the appropriate setting it may be best to allow time for the proteinuria to resolve, rather than continuing or escalating immunosuppression in an attempt to hasten recovery.

JOANNE M. BARGMAN, MD, FRCPC, Department of Nephrology; CARMEN AVILA-CASADO, $\mathrm{MD}, \mathrm{PhD}$, Department of Pathology, University Health Network, University of Toronto, Toronto, Canada.

Address correspondence to Dr. Bargman, University Health Network, 200 Elizabeth Street, 8N-840, Toronto, ON CANADA M5G 2C4. E-mail: joanne.bargman@uhn.ca

\section{REFERENCES}

1. Touma Z, Urowitz M, Ibanez D, Gladman D. Time to recovery from proteinuria in patients with lupus nephritis receiving standard treatment. J Rheumatol 2014;41:688-97.

2. Bargman JM. Why are rheumatologists treating lupus nephritis? Nat Clin Pract Nephrol 2007;3:296-7

3. Hagemann JH, Haegele H, Müller S, Anders JH. Danger control programs cause tissue injury and remodeling. Int J Mol Sci 2013;14:11319-46.

4. Iwata Y, Bostrom EA, Menke J, Rabacal WA, Morel L, Wada T, et al. Aberrant macrophages mediate defective kidney repair that triggers nephritis in lupus susceptible mice. J Immunol 2012;188:4568-80.
5. Sachs N, Sonnenberg A. Cell-matrix adhesion of podocytes in physiology and disease. Nat Rev Nephrol 2013;9:200-10.

6. Yuan H, Takeuchi E, Salant DJ. The podocyte slit-diaphragm protein nephrin is linked to the actin cytoskeleton. Am J Physiol Renal 2002;282:F585-F591.

7. Migliorini A, Ebid R, Scherbaum CR, Anders HJ. The danger control concept in kidney disease: mesangial cells. J Nephrol 2013;26:437-49.

8. Shankland SJ, Anders HJ, Romagnani, P. Glomerular parietal epithelial cells in kidney physiology, pathology, and repair. Curr Opin Nephrol Hypertens 2013;22:302-9.

9. Helal I, Fick-Brosnahan GM, Reed-Gitomer B, Schrier RW. Glomerular hyperfiltration: Definitions, mechanisms and clinical implications. Nat Rev Nephrol 2012;8:293-300.

10. Brahler S, Ising C, Hagmann H, Rasmus M, Hoehne M, Kurschat $\mathrm{C}$, et al. Intrinsic proinflammatory signaling in podocytes contributes to podocyte damage and prolonged proteinuria. Am J Physiol Renal Physiol 2012;303:F1473-F1485.

11. D'Agati VD, Kaskel FJ, Falk RJ. Focal segmental glomerulosclerosis. N Engl J Med 2011;365:2398-411.

12. Beck LH, Jr, Salant D. Membranous nephropathy: recent travels and new roads ahead. Kidney Int 2010;77:765-70B.

13. Nangaku M, Couser WG. Mediators of renal injury in membranous nephropathy. Arch Med Sci 2009;5-3A:S451-S458

14. Pippin JW, Durvasula R, Petermann A, Hiromura K, Couser WG, Shankland SJ. DNA damage is a novel response to sublytic complement C5b-9-induced injury in podocytes. J Clin Invest 2003;111:877-85.

15. Mundel P, Shankland SJ. Podocyte biology and response to injury. J Am Soc Nephrol 2002;13:3005-15.

16. Arndt TP, Pippin J, Durvasula R, Pichler R, Hiromura K, Monkawa $\mathrm{T}$, et al. Mechanical stretch induces podocyte hypertrophy in vitro. Kidney Int 2005;67:157-66.

17. Beck L, Bonegio R, Lambeau G, Beck D, Powell D, Cummins T, et al. M-Type phospholipase A2 receptor as target antigen in idiopathic membranous nephropathy. N Engl J Med 2009; 361:11-21.

18. Moroni G, Quaglini S, Gravellone L, Gallelli B, Leoni A, Messa P, et al. Membranous nephropathy in systemic lupus erythematosus: long-term outcome and prognostic factors of 103 patients. Semin Arthritis Rheum 2012;41:642-51.

19. Radhakrishnan J, Moutzouris D, Ginzler E, Solomons N, Siempos I, Appel G. Mycophenolate mofetil and intravenous cyclophosphamide are similar as induction therapy for class $\mathrm{V}$ lupus nephritis. Kidney Int 2010;77:152-60.

20. Appel G, Contreras G, Dooley M, Ginzler E, Isenberg D, Jayne D, et al; Aspreva Lupus Management Study Group. Mycophenolate mofetil versus cyclophosphamide for induction treatment of lupus nephritis. J Am Soc Nephrol 2009;20:1103-12.

21. Houssiau F, D’Cruz D, Sangle S, Remy P, Vasconcelos C, Petrovic R, et al; MAINTAIN Nephritis Trial Group. Azathioprine versus mycophenolate mofetil for long-term Immunosuppression in Lupus Nephritis: Results From the MAINtain Nephritis Trial. Ann Rheum Dis 2010;69:2083-9.

22. Dooley M, Jayne D, Ginzler E, Isenberg D, Olsen N, Wofsy D, et al. Mycophenolate versus azathioprine as maintenance therapy for lupus nephritis. N Engl J Med 2011;365:1886-95.

J Rheumatol 2014;41:622-5; doi:10.3899/jrheum.140157 